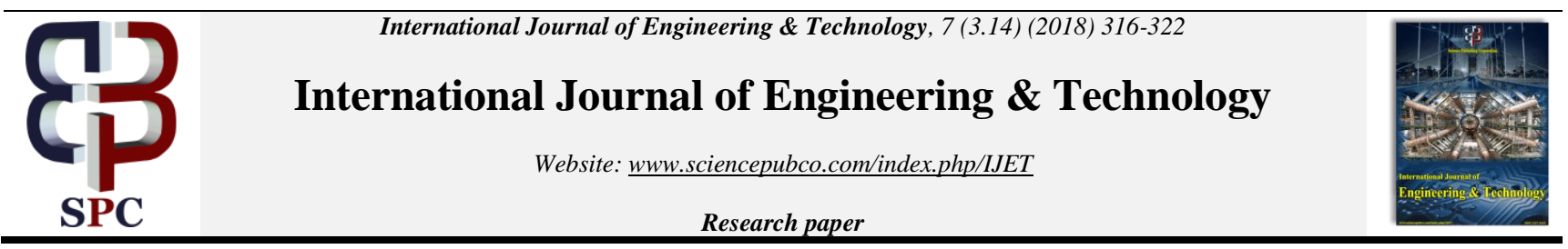

\title{
Model Of The Russian Crypto Currency Exchange Market
}

\author{
Vladimir Alexandrovich Galanov1, Denis Grigorievich Perepelitsa2, Alexandra Vladimirovna Galanova3, Natalia \\ Fedorovna Chelukhina4, Elmira Ahmetshaevna Asyaeva5
}

\author{
1Plekhanov Russian University of Economics \\ Stremyanny Lane, 36, Moscow, 117997, Russia \\ 2 Plekhanov Russian University of Economics \\ Stremyanny Lane, 36, Moscow, 117997, Russia \\ 3 National Research University Higher School of Economics (HSE) \\ Myasnitskaya Street, 20, Moscow, 101000, Russia \\ 4Plekhanov Russian University of Economics \\ Stremyanny Lane, 36, Moscow, 117997, Russia \\ 5Plekhanov Russian University of Economics \\ Stremyanny Lane, 36, Moscow, 117997, Russia
}

\begin{abstract}
In recent years, a new market trading in cryptocurrencies and instruments based on them has been formed. Its participants who are interested in it according to the rules they develop create the market of cryptocurrencies. The goal of this article is to substantiate the possibility of a more organized market of cryptocurrencies with its legitimate exchange market in its top with two possible versions: a) as a specific exchange market consisting of an exchange center and decentralized markets (exchanges) of certain cryptocurrencies and b) as a market of cryptocurrencies built in into certain segments of the already existing exchange markets. Functional aspects of creating the cryptoinstruments' exchange market are considered, and possible models of organizing it are offered. The authors are based on the need to strengthen the regulatory participation of the state during the formation of this market because such participation allows better observance of public interests under the conditions when the private interest is a driving force of the market. The state regulation somehow minimizes financial risks for ordinary participants of the cryptocurrencies' market, but at the same time limits the impact of the new market towards possible destabilizing effects on the monetary circulation in the country and on the current investment processes in it.
\end{abstract}

Keywords: exchange, exchange market, cryptocurrency, cryptomarket, cryptoassets, cryptographic platform, model of cryptomarket.

\section{Introduction}

One of the most interesting and controversial trends in the development of the modern market is the occurrence and rapid growth of the cryptocurrency market, or cryptomarket in short. This area of the modern economy attracts the greatest attention of many economists $[6,10,14]$.

The goal of the majority of participants in the new market is to obtain net income (profit). This goal is best achieved when the market is developed spontaneously, and its participants are not limited either in their actions or in their monetary income, above all in terms of taxation. However, the history shows that the spontaneous development of the market inevitably causes monopolization and concentration of capital owned by a small number of individuals. It is associated with the oblivion of many social needs of the society, where and due to which there is a market. That is why since the very beginning the occurrence of the cryptomarket has been under close attention of the state that strives to limit the spontaneous development of such market in one regulatory way or another, and to regulate its functioning and consequences of this functioning from the positions that allow finding a certain compromise between personal wishes of the market participants and public needs.

\section{Methods}

\subsection{Urgency}

The urgency of the issues related to cryptocurrencies has two sides. On the one hand, it goes about the research urgency Finally, without some common understanding of what cryptoinstruments are on the market, it will not be possible to create the necessary and sufficient regulatory framework for their legitimate circulation and public regulation. On the other hand, the urgency of cryptoinstruments has a practical nature because their actual availability on the market means the emergence of a specific financial asset, the purchase and sale of which can provide traders with high revenues. Cryptocurrencies are the actual reality of the modern financial market $[13,18]$.

Since the market of cryptocurrencies is referred to financial markets, it must also be taken into account in certain program documents of the government (state). On the one hand, the recent emergence of the cryptomarket did not allow, for example, specifying it in the previously adopted concept of developing the Russian financial market until 2020 [3]. However, on the other hand, at the beginning of 2018 two drafts of Russian laws related to this market were prepared for discussion and improvement [11, 12]. 
The actual development of the cryptocurrency market causes changes in the "architecture" of the modern financial market itself. The same is caused by the growth of the economic power of China and other developing markets [9].

In his famous book 'Currency Wars', Song Hongbing emphasized the competition between the dollar and the yuan on the world market [8], but judging from the recent events, the same "war" threatens the modern market in the form of confrontations between the fiat money and cryptocurrencies.

\subsection{Goal and Tasks}

The goal of this article is to find approaches to improving the regulation of the existing cryptocurrency markets. To achieve this goal, it is necessary to

- Analyze opportunities of organizing regulated cryptomarkets,

- Identify possible areas for the development of the legitimate cryptocurrency exchange market, and

- Substantiate possible variants of the cryptocurrency exchange market models.

\subsection{Research Object and Subject}

The object of the study is the exchange financial market as a market where, first of all, currencies, securities, derivative financial instruments are traded.

The subject of the study is models for creating a legitimate exchange market that covers relations related to the sale and purchase of cryptocurrencies and instruments derived from them.

\subsection{Research Methods}

The conducted research is theoretical and is based on using the laws of formal logic, analysis and synthesis, induction and deduction, analogy and modeling. Due to using these methods, the research object under analysis can be viewed from different sides, which allows studying its various features and properties, connections and relationships.

\subsection{Research Novelty}

The research novelty of the study is in the substantiation and consideration of variants for organizing a legitimate cryptocurrency exchange market that takes into account the specificity of the initial exchange commodity - the cryptocurrency, and peculiarities of its circulation under modern conditions.

\section{Results}

\subsection{Variants of the legitimate Cryptocurrency Exchange Market}

Cryptocurrencies are sold and bought on the existing electronic platforms called "cryptocurrency exchanges", although the majority of them usually do not have any legal rights to be called "exchanges". In this case the name "exchange" suits all participants of the cryptocurrency market because it is a "place determinant" or a "marker" for these participants where they can buy and sell (exchange) their cryptocurrencies according to the rules generally accepted on this market. In other words, cryptocurrency traders merely objectively need some common "places" where they could "meet" and make transactions with cryptoassets.

It is obviously that an analogue of this "exchange" market of cryptocurrencies is the existing foreign currency market where national currencies are exchanged. This currency market always has a national binding to its participants. However, by the essence of its product it is an international market that organizationally exists primarily in the form of interbank national and international mar- kets (FOREX market). The exchange form of the foreign currency market organization makes sense only as a national currency market because in this variant, the state, whose role in this case is to observe certain national interests (interests of a certain country), can have an impact on it. At the same time, the world (international) nature of the foreign currency market, at least now, makes it impossible to establish one (single) "world" currency exchange that would be inevitably based in a particular country, and thereby the world market to any extent would be "controlled" by the country where it is located.

In contrast to the foreign exchange market, the "global" market of cryptocurrencies has its main organizational form of existence. These are cryptocurrency exchanges established by the market participants themselves. They are "supranational", and therefore they do not necessarily exist under any national legislation. The organizers of such exchanges operate in the Internet. That is why they do not "need" any permission from the state.

It is possible to explain it by two important points: on the one hand, the need in specialized cryptocurrency exchanges - places to exchange cryptocurrencies that are common for all cryptocurrency owners, and, on the other hand, the nonparticipation of commercial (and central) banks in this market as trading participants due to legal reasons. In their turn, the roots of these legal reasons are in the fact that the legality of cryptocurrencies has not yet been properly achieved and the central bank (the "state") is not a cryptocurrency issuer.

Under the Russian conditions, the regularity of the cryptocurrency market (cryptomarket) is an important aspect not only in terms of its creation, but also in terms of maintaining the confidence of potential market participants in minimizing and preventing the spread of fraud (deception of market participants) and insider trading on this market.

The Russian investor's psychology is focused on a rapid increase in his personal (private) capital, but, as many market professionals note, at an insufficiently high level of the population's financial literacy [4]. Ordinary people influenced by the available information get an idea that the cryptocurrency is almost an analog of gold [15]. Hence, the so-called well-known Internet popularizers of cryptocurrencies, for example, A. Antonopoulos, become important $[1,2]$.

The absence or lack of the required regulatory instruments and controlling organizations can result in large savings losses for many individuals who are participants of the cryptomarket. It can cause massive disappointment of the investor traders in the fair pricing of cryptocurrency assets (instruments), and all this can eventually become an obstacle for the development of this market. According to the authors of the article, the most relatively simple and quick way to organize a legitimate national cryptocurrency exchange market is a variant of the complementary exchange market. In this case, the cryptocurrency exchange market is formed on the basis of the legitimate exchanges that already exist in the country. The preference of such model of formation and further development, for example, of the Russian or merely national cryptocurrency market is determined by the fact that this variant does not require to again create many common elements of the infrastructure required by the modern financial market. In addition, if cryptocurrencies (cryptoassets) are considered as a new form of the competitive asset existence along with the already available financial assets, it can become a factor of the trading activity growth on the existing financial markets ("platforms").

In Russia, the main trading platform for financial assets is the Moscow Stock Exchange (MSE) that is focused on trading securities, currency, and derivative financial instruments.

The centralization of the financial market on a single trading platform greatly simplifies all processes of its management and regulation, both from the market participants themselves, and from the state, first of all, the Bank of Russia as the main regulator of the financial market according to the law. 
The Russian cryptocurrency exchange market is interpreted as the market of various cryptoassets to the degree of the Russian regulation (control) by the MSE and the Bank of Russia.

According to the authors, the most acceptable variant for Russia is the creation of its own (national) regulated cryptomarket but built into the already existing financial market and simultaneously developing according to the norms generally accepted both for the international (world) cryptoassets' market, or international cryptomarket that includes decentralized platforms for trading cryptocurrencies that already exist in the world [1].

The main provisions of the offered exchange model of the cryptomarket include the following:

Initial creation of the center (the "core") of the cryptomarket in the form of an exchange market that is common for all participants,

Possibility of the further formation of local, i.e. isolated from the center, cryptomarkets on the basis of licensed professional participants of the securities' market,

Selection of the initial trading market participants based on the principles of professionalism and competence and prevention of forming the market with professionally unprepared participants at the initial stage, and

Formation and improvement of the market in close connection with the world (international) cryptomarket based on:

a) Convergence of forms and methods of regulating and controlling this market,

b) Regulation of the process on admitting foreign participants to the Russian cryptomarket and Russian participants on the world cryptomarket, and

c) Regulation and/or control over the processes of cryptoassets moving from the Russian market to the world market and backwards.

\subsection{Internationality and Nationality of the Russian Cryptocurrency Exchange Market}

The concept of own (national) market is specific by the fact that it includes, first of all, the components having the national character. However, the embeddedness of any Russian market in the international (world) market arguably means that at the same time it has an international nature, too. Thus, by analogy it is possible to conclude that the Russian cryptomarket in all its variants has or will have an international nature, i.e. it will be an integral part of the world cryptomarket.

In the most general form, the internationality of the Russian cryptomarket can be described as follows:

Internationality of participants of this market is ensured by the availability of the Russian market for foreign participants and the availability of foreign markets for the Russian participant, Internationality of the market instruments is ensured by the fact that participants of the Russian market have also access to nonRussian cryptoinstruments,

Internationality of the market organizers is ensured by the similarity of the basics of organizing the Russian cryptocurrency exchange market and non-Russian cryptocurrency exchange, and Internationality of the market regulators is ensured by the similarity (commonality, unity) of basics for regulating the Russian market and foreign markets.

\subsection{Components of the Cryptocurrency Exchange Market}

Like any other market, the cryptomarket includes the unity of its four sides (parts):

Market participants,

Assets (instruments) of the market and operations with them,

Market organizers, and

Market regulators.

Participants of the cryptomarket: individuals and legal entities. In the market economy, the relations between owners are carried out through the market, i.e. through the relations of purchase and sale.
And since all individuals and legal entities are owners, all of them are to some extent participants of the market in general. The cryptomarket is new (the latest) but still a part of the modern market due to the fact that its participants also enter into purchase and sale relations. That is why its potential participants will be objectively both individuals and legal entities because there are no other potential participants of the market.

Certainly, with a flow of time, or as the market develops, the number and composition of the participants of the cryptomarket will expand, on the one hand. On the other hand, for various reasons, there may be some restrictions related to the participation in this market for some types of individuals and/or legal entities, for example, collective investors.

Now main participants of the cryptomarket are individuals who are least subject to the state legislative regulation as compared to legal entities whose activity is more subject to state regulation than actions of individuals.

From the perspective of the pursued goals of individuals as participants of the cryptomarket, it is possible to classify three main (principle) groups:

Traders who use cryptocurrencies to promote their goods to consumers or to purchase goods, the trading of which on markets is difficult,

Speculators who play on raising or lowering the rate of the cryptocurrency (cryptocurrencies) to earn profit, and

"Savers" ("hedgers", "investors") are individuals who use the cryptocurrency for various personal purposes related to maintaining their fiat monetary savings, for example, if the national currency is highly depreciated.

However, as the legal problems on the existing and functioning of the cryptomarket are solved, the participation of legal entities on this market will inevitably increase.

Initially, the main type of legal entities participating in the cryptomarket is commercial banks. It is impossible to trade cryptocurrencies without them, e.g. when providing the relation between cryptocurrencies and fiat money, and therefore paying for goods and services with cryptocurrencies. Now banks as participants of the cryptomarket are specific by their belonging primarily to the objectively necessary infrastructure of this market, and not directly to its trading participants. If the banks ceased (or they were prohibited) to provide, even indirectly, the exchange of cryptocurrencies for fiat money, the cryptomarket would not be able to exist in its present form at all. No authorized purchase and sale of goods for cryptocurrency is possible without the bank participation. Without banks, the cryptocurrency cannot even become money on the illegal commodity market because sellers of illegal goods still need fiat money. That is why the exchange of cryptocurrency for legal payment means is a prerequisite for the existence any kind of illegal commodity market as well.

The second necessary type of the legal entity as a participant of the cryptomarket is companies that use cryptoinstruments to raise investments in the form of fiat money for their commercial projects. The main driver for the development of such companies is the possibility of a rapid increase in the capital of investors, not because of the efficiency (results) of the investment project itself, which usually takes a long time, but because of the growth of the cryptocurrency rate

Market instruments. In terms of its instruments, to a great degree the cryptomarket resembles the modern financial market. That is why it is necessary to foresee the following components in it:

Market of actually cryptocurrencies a) the cryptocurrency exchange, and b) the exchange of cryptocurrencies for the fiat currencies,

Market of share (debt) obligations of cryptoprojects. This market will also be called the "token market" ("cryptoshares"). However, it does not deny the fact that in case of legalizing cryptocurrencies, any traditional securities can be issued on the blockchain platform even if they are denominated in a cryptocurrency. It is possible to say that the token is an analogue of a share (bond) only as a transitional (temporary) step until the market determines the 
relationship between the fiat money and the cryptocurrency and, in general, the essence of the cryptocurrency [5],

Market of derivative financial instruments (DFI) for cryptocurrencies (tokens). Futures contracts for Bitcoins in the US are a vivid example of such market.

Organizers of the market. They can vary considerably depending on the nature of the cryptoasset. Thus, derivative financial instruments for cryptoassets are completely independent of the mode of the cryptoasset existence that acts only as the basic asset of a termed contract. In other words, derivative tools for cryptoassets themselves are not yet cryptoassets. That is why the market of futures or options for cryptoassets automatically "occurs" on the basis of the already existing exchange market of derivative financial instruments [16].

The situation is different with cryptocurrencies and cryptoshares that do not exist in the same form as ordinary securities because they are inseparably related to cryptographic platforms and therefore need their own organizational forms of the market.

As applied to the Russian conditions, it is possible to assume the possibility of two types of the cryptomarket organizers: the central organizer represented by the MSE and local market organizers that can be professional trading participants of the modern securities' market, represented, above all, by brokerage companies in their broad sense as commercial organizations that perform the functions of brokers, dealers and management companies on the modern financial market. Such division can reduce the risks associated with the bankruptcy of private cryptocurrency exchanges, just as it has already happened in the recent history of the cryptomarket [19]

The division of the organized cryptomarket into its "center", or the central exchange market, and its local exchange markets organized by professional market participants, as there is a need in such markets, will allow expanding the range of traded cryptoassets that can be regulated (controlled) by the market community. According to the practice of any modern exchange financial market, the range of assets traded on it is very small in relation to the total number of existing (issued) assets. Since the creation of cryptoassets on the basis of blockchain platforms can potentially be very large, the central market is unlikely to be able to meet trading needs of all cryptocurrencies (cryptoassets). Ultimately, the most "major" and "interesting" assets will be concentrated on it for permanent traders. As for other less traded assets, the creation of local markets is possible. This is where groups of other, more specialized cryptoassets will be traded from time to time.

The possibility of creating local cryptocurrency exchange markets can also be explained by the fact that cryptoassets can be created not only for "ordinary" investment, or attraction of capital. However, such assets can become a component of assets of, for example, insurance or credit markets, or services markets. It seems that such not entirely investment nature of this kind of cryptoassets can cause the need to create, so to say, "commodity-financial" markets where "non-investment" cryptoassets will be exchanged for investment cryptoassets, and these cryptoassets can already get to the central cryptomarket.

In other words, due to the specificity of the cryptoasset itself as compared to other financial assets, it is necessary to immediately foresee the possibility of its functioning as a market where the MSE is only its highest center, the highest level of trade organization that has the required relations with local centers to trade cryptocurrencies depending on their specificity and purpose.

Market regulators. This concept includes two sides:

a) Regulators as organizations,

b) Regulators as statutory enactments: laws and other necessary regulatory documents.

The cryptomarket is a market based on cryptographic platforms, and in this sense, it is always a self-regulated market in relation to participants of such cryptographic platforms. However, since any market participants are under the jurisdiction of the relevant countries, there is inevitably a clash of interests of participants from some countries with participants from other countries, or even interests of participants on this market with the ones of other markets. It is possible to establish a balance of economic interests between private market participants only on the basis of the regulating and controlling participation of the state represented by the financial regulation bodies appointed by it. In Russia, the main regulator of financial markets is the Bank of Russia. The expansion of its regulatory powers to the cryptomarket is largely based on the fact that in the future it will play a decisive role in establishing the parity between fiat money and cryptocurrencies. The Central Bank is the issuer of the existing fiat money, i.e. legal means of payment. That is why it has a direct interest in resolving the issue on participation or nonparticipation, or on the limits of the cryptocurrencies participation in the commodity-money circulation of the country.

This is the function of the legislative bodies of the state power to develop and adopt the required regulatory acts in the form of laws. Their main task at the stage of the Russian cryptomarket formation is to make the necessary "order" in the composition and content of the regulatory documents required for the functioning of such market, and that would initially allow defining participants, instruments (areas of existence) and transactions of this market. Many authors agree that the cryptomarket and its instruments should be built in into the system of state administration [17].

\subsection{Organizational Model of the Russian Cryptomarket}

Conceptually, the model of the regulated cryptocurrency exchange market covers the opposites that are peculiar of all most important components of the market and that are related to the nationality and internationality of the market, its exchange and nonexchange nature, its regulatory and nonregularity (degree of regulatory) and other market parties whose practical combinations with one another can ultimately be established only on the basis of the cryptomarket functioning. 


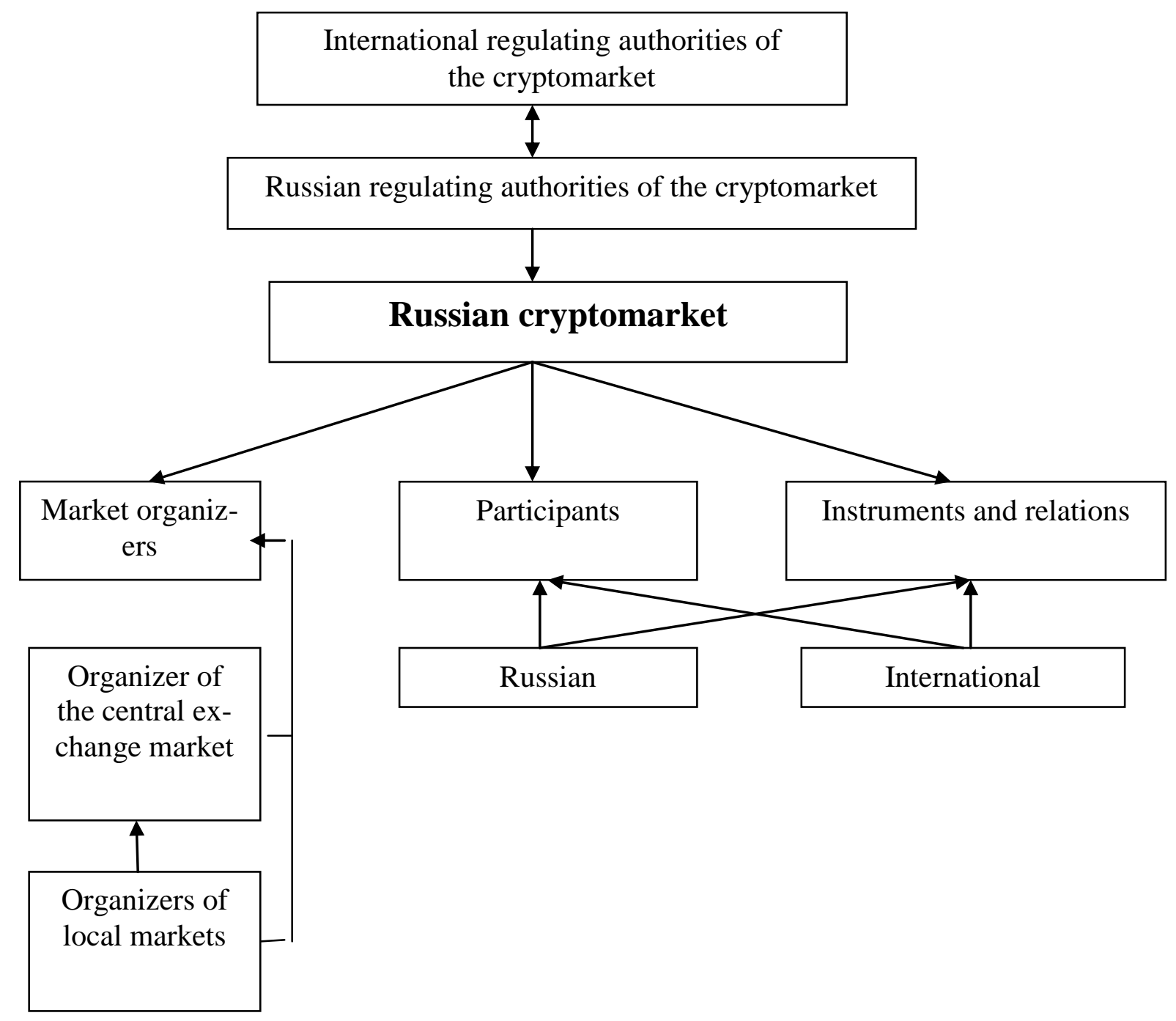

Fig.1. Organizational Model of the Russian Cryptomarket

The organizer of the central market of cryptoassets can be the MSE as an organizer of the top level of the cryptomarket in terms of the cryptocurrency exchange, issue of cryptoshares, and trade of derivative financial instruments on the basis of cryptoassets. The MSE:

a) Becomes the national market of cryptocurrencies accessible to all participants that is potentially more reliable due to the most legitimate and leading status of the exchange as compared to other private electronic platforms,

b) Can act as an intermediary between Russian participants of the market and international markets of cryptocurrencies. For example, Russian participants can withdraw their cryptoassets from foreign trading platforms and store them in electronic wallets at MSE, and

c) Becomes a "selective" ("listing") platform to issue cryptoshares of Russian start-ups raising investments by using cryptocurrencies.

International electronic exchange markets of cryptocurrencies like foreign markets remain accessible for Russian participants but it means that they simultaneously play the role of competitors of Russian trading platforms.

Participants of the world and Russian cryptomarkets are expected to be any individuals and organizations. However, as for the Russian segment of the cryptomarket, it is necessary to set certain restrictions as for the possibility of Russian nonprofessional and/or unqualified participants to work on them in order to ensure the protection and safety of their investments in cryptoassets. It is possible not to introduce such restrictions for foreign traders, as well as there are no restrictions for Russian investors on international cryptomarkets.

However, it is necessary to strive for extending participants of the cryptomarket in addition to the individuals who risk only their own savings and capital towards extending the participation of commercial organizations in trading on the cryptomarket.

Initially, two groups of companies can be allowed to trade in Russian cryptoassets:

a) Commercial banks that have strong professional traders and particularly need new profitable (speculative) market instruments along with derivative financial instruments. The matter is that banks as they legalize cryptoassets will still work with them for profitable purposes, but if there is no national market, they will do it outside of it.

b) Companies issuing tokens (cryptoshares) and companies that buy such assets. It is desirable for the market of Russian cryptoassets that are similar to shares and bonds to immediately develop on the central (single) platform as well. However, it must be done not to create difficulties for investments of non-Russian individuals and entities in such assets.

The "line" of cryptoassets' types has already been more or less formed on the world market of cryptocurrencies. However, there are thousands of the cryptocurrencies, which makes it impossible to trade them. This is exactly the same as the number of issued shares potentially amounts to tens and hundreds of thousands, and the number of their traded types, especially blue chips, is relative- 
ly small. On the financial market, two opposite processes are usually intertwined: the individualization of assets and their tradability (liquidity). Possibilities for the asset individualization exceed the ones of their turnover. By itself, the need in such individualization makes it almost unnecessary to trade them because the relevant financial asset remains in the investor's ownership for various reasons for a long time, mainly also related to maintaining its ownership or for the purpose of obtaining a systematic profit in the future. That is why the market spontaneously allocates only some groups of assets that are actively traded. The same is observed in trading cryptocurrencies. Their large number includes only a few tradable cryptocurrencies, for example, Bitcoin, Ethereum,Litecoinetc

\subsection{Functional Model of the Exchange Cryptoassets' Market}

In terms of the relationship between cryptoassets and fiat money, it is possible to offer the following functional model of the Russian cryptocurrency exchange market (Fig. 2).

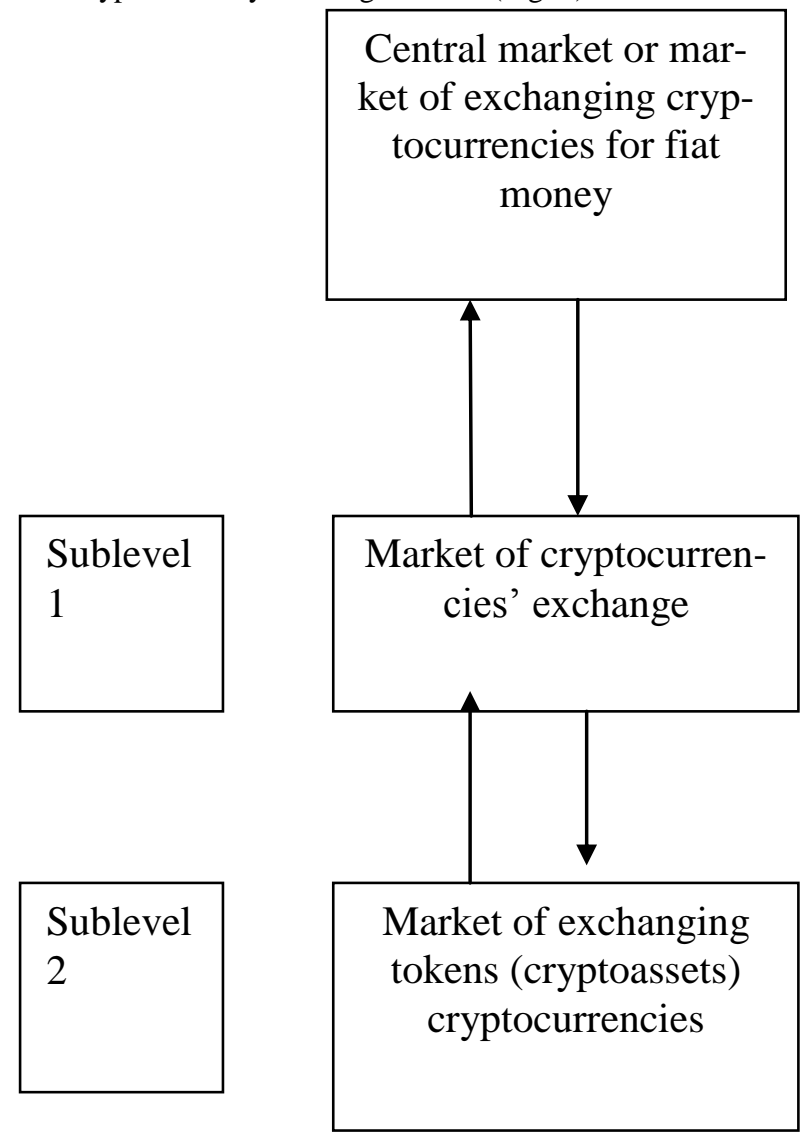

Fig. 2. Functional Levels of the Russian CryptomarketThe relations between cryptocurrencies (cryptoassets) and fiat

Money are of key importance now. Consequently, this type of relations must to the greatest degree be centralized and focused on the single market, for example, at the MSE for financial regulators to fully control and coordinate the impact of the cryptoassets' development and trading on the existing monetary circulation in the state (in the economy), and not to allow any possible and still unknown negative processes on money circulation, financial area and economy, as a whole.

The next level of the cryptomarket is the exchange of cryptocurrencies ("cryptomoney"). This level is necessary for the participants of the cryptomarket to search for "substantiated" ("correct") proportions of exchanging one cryptocurrency for another. It will contribute to building reasonable proportions of the cryptocurrency exchange in the cases when the cryptocurrency does not directly enter the central market, i.e. when there is no systematic market for its exchange for fiat money, but, nevertheless, there is an exchange of this "ordinary" cryptocurrency for the cryptocurrency traded on the central market, i.e. for the "central cryptocurrency". At the same time, in terms of the mutual impact of the central market and its first sublevel, on the central market there will be a sort of verification of the correctness of determining the proportions of the exchange of one "central" cryptocurrency for another identical cryptocurrency.

There will be relatively few central (principal, liquid) cryptocurrencies, and by trading on the first sublevel of the market all other cryptocurrencies will be equated to central cryptocurrencies, and to the fiat money through them. The proposal comes to the need to have a two-stage procedure of exchanging cryptocurrencies for fiat money: such exchange is directly available only on the central market and only for "central" cryptocurrencies, while all other cryptocurrencies must first be exchanged for central cryptocurrencies at their sublevel and for fiat money by using them.

The independent sublevel of the cryptomarket functioning (second in Figure 2) covers the relations among cryptoassets in the form of tokens and cryptocurrencies. As applied to tokens, obviously it will be possible to use two ways of organizing their market.

The first way is to allow direct exchange of the issued tokens for fiat money for the group of cryptoissuer companies that meet the requirements of the regulating authority. In this case, the issue of tokens becomes an element of the central exchange market and is made according to the issue rules that are close to

the existing order of securities' issue that aims at protecting investors from various types of "unreliable" issuers.

The second way is a facilitated way of issuing tokens, especially for small companies that start their operation and start-ups in the digital economy, based on the issue of cryptoassets. These are the companies that are issuers of the cryptomarket that need the second sublevel of the market where very high risks peculiar of any new asset market (on the analogy of the venture business) are maintained. On this market, tokens' issuers can initially sell them only for the existing central and other cryptocurrencies. The amounts of cryptocurrencies obtained this way can be subsequently exchanged for fiat money.

On the one hand, such two-stage model of obtaining fiat money on investment cryptoprojects will contribute to developing the turnover of the cryptocurrency market. On the other hand, it will make it more difficult to create (offer) "unreliable" investment projects because it prolongs the procedure required for obtaining fiat money, for which such projects in the digital economy are usually offered.

\section{Discussion}

On the one hand, the scientific and practical interest in the development of cryptocurrencies and cryptomarkets is substantiated by their novelty and specificity, focus on digital technologies in the financial area. On the other hand, there are no enough actual scientific researches and developments in this area because the market community mainly focuses on how it is possible to earn on the growth (or fall) of cryptocurrencies' rates, or how to maximize the attraction of dollar (fiat) investments in cryptoprojects based on selling relevant tokens. In fact, this is the latter aspect of the economic application of cryptocurrencies that stimulates extremely high importance of various economic and legislative problems associated with them.

In terms of the problem under consideration related to the models of the exchange organization of the cryptomarket, it is possible to state that it is necessary to refer the existing level of this market organization to the often-called types of reasons for high volatility of cryptocurrencies' rates. For example, it is specified in the note "Five reasons why cryptomarket has collapsed again" [7]. 


\section{Conclusion}

The obtained results and recommendations can be used by participants of financial markets, financial regulatory authorities and law making bodies to establish boundaries and areas for the further development of the national cryptoassets' market, to define certain economic and/or legal participants of the already existing financial markets in it, including individuals, to develop the infrastructure of financial markets, and to develop the relations of the cryptomarket with other markets and market structures. The study makes a feasible contribution to the necessity of ensuring the macroeconomic sustainability of the modern market economy, while it focuses on creating conditions that contribute to the further growth of trading activity on financial markets, increase in their investment attractiveness by using new "digital assets" based on cryptographic platforms.It is possible to continue developing theoretical provisions and instruments of cryptocurrency exchange market in the following areas:Further enhancing of understanding the specificity of the exchange organization of the cryptomarket, its participants and instruments,Formation of the necessary legal basis for the cryptocurrency exchange market in conjunction with the existing regulatory framework of the exchange market, andStrengthening of relations of the cryptocurrency exchange market with other exchange financial markets. The development of the cryptocurrency exchange market (cryptomarket) appears to be one of the required conditions and prerequisites for forming a digital economy of the future.

\section{References}

[1] A. Antonopoulos. O detsentralizovannyh birzhakh [On decentralized exchanges]. 2017. Available online: https://golos.io>knigi-poblokcheinu

[2] A. Antonopoulos. Ovladeniye bitkoynom [Mastering Bitcoin]. 2017. Available online: https://golos.io>knigi-po-blokcheinu

[3] Concept of developing the financial market of Russia until 2020. Available online: http://www.asros.ru/publik/elfinder/files/news/docs/27-0808_01.pdf

[4] S. Digo. Granitsy poleznosti finansovoy gramotnosti naseleniya [Boundaries of the usefulness of financial literacy of the population]. Bulletin of the Rector of the Plekhanov University, 2(80), 2015.

[5] A. Dubyansky. Teorii proiskhozhdeniya deneg i kriptovaliuty [Theories of the money and cryptocurrency origin]. Money and Credit, 12, 2017, pp. 97-100.

[6] M.V. Egorova. Kriptovalyuta kak novaya realnost [Cryptocurrency as a new reality]. International Economics, 11, 2017, pp. 34-41.

[7] Five reasons why cryptomarket collapsed again. Available online: https: //ru/insider.pro/

[8] S. Hongbin. Voyna valyut. Pered burey [The war of currencies. Before the storm]. Publishing house of the ROO "Russian Choice", 2015.

[9] A.N. Kirillov, E.N. Balaganskaya. Izmeneniye mirovoy finansovoy arkhitektury [Change in the world financial architecture]. Fundamental Research, 11, 2015.

[10] M. Kulakov. Kriptovalyuta kak lokomotiv sovremennogo etapa finansirovaniya mirovoy ekonomiki [Cryptocurrency as a locomotive of the current stage of financing the world economy]. International Economics, 1, 2018, pp. 50-57.

[11] On digital financial assets. Bill of the Ministry of Finance of the Russian Federation. Available online: http://www.minfin.ru/en/document/File/?id_4-121810

[12] On alternative ways to attract investment. Bill of the Central Bank of the Russian Federation. Available online: http://www.cbr.ru/content/Document/File/35809/20180125_02.pdf

[13] T.A. Panova. Kriptovaliuty i blokcheyn - realii sovremennosti. Rossiya i Kitay: vyzovy i perspektivy mezhdunarodnoy integratsi [Cryptocurrencies and blockchain are the modernity realities. Russia and China: challenges and prospects for international integration]: Proceedings of the International Research and Practical Conference. Moscow: Plekhanov Russian University of Economics, 2017.
[14] V.A. Popov. Obshchiye tendentsii razvitiya tekhnologii i filosofii blokcheyna $\mathrm{v}$ blizhayshiye gody [General trends in developing the technology and philosophy of blockchain in the coming years]. Banking, 3(289), 2018, pp. 14-19.

[15] N. Popper. Tsifrovoye zoloto. Neveroyatnaya istoriya Bitkoyna ili o tom, kak idealisty i biznesmeny izobretayut dengi zanovo [Digital gold. Incredible story of Bitcoin or how the idealists and businessmen are inventing money again]. Williams Publishers, 2016.

[16] I. Shaker. Evolyutsiya prirody tsifrovykh aktivov: fyuchersy na Bitcoin [Evolution of the nature of digital assets: futures for Bitcoin]. Finance, Money, Investments., 4, 2017, pp. 27-32.

[17] D. Statovsky, E. Statovskaya. Blokcheyn i kriptovalyuta s sisteme gosudarstvennogo upravleniya [Blockchain and cryptocurrency in the system of public administration]. Budget, 12, 2017, pp. 50-54.

[18] A. Tepper. Bitkoyn - dengi dlya vsekh. [Bitcoin - money for everyone]. 2017. Available online: criptonica.com

[19] Vzlet i padeniye Shelkovogo Puti [The rise and fall of Silk Road] Available online: https://bits.media/silk-road/.

[20] R.M. Yankovsky. Problema pravovogo regulirovaniya kriptovalyut [The problem of legal regulation is cryptocurrencies]. Law and Business, 1, 2018, pp. 45-51. 